\title{
Walt Disney's Influence on the Fairy Tale Genre in Contemporary Mass Literature
}

\author{
Ekaterina Zueva \\ Kazan Federal University
}

\begin{abstract}
Walt Disney's animation influenced the further fairy tales plot interpretation not only in cinema but also in literature. Many cruel details of original fairy tales were omitted by screenwriters of Disney studio to make movies available to children.

The theme of heroes and villains, motivation of their actions and unexpected point of view becomes the common traits of contemporary fairy tale. The well-known plot is told from the point of view of the negative character. The plot doesn't undergo significant changes, however many details which were removed or, on the contrary, are added by Disney studio, remain invariable. Among the most interesting transformations the image of the Evil Fairy from the fairy tale by Charles Perrault "Sleeping Beauty" seems to be the most interesting. Walt Disney creates an expressive visual image of the evil sorcerer Malificent in his cartoon of 1959. In 2014 the Disney studio releases the movie "Malificent" in which it is told how the history of treachery caused all events which are taking place in the fairy tale. Soon after a release of the movie the novelization of Elisabeth Rudnik of the same name was released, where not only justification was given to Malificent's actions but also the whole story was shown through her eyes.

There is the following chain: the classical literary fairy tale forms the basis of Disney's interpretation, and then the new literary text is created according to the cinematic variant.
\end{abstract}

Keywords: cartoon; image; interpretation; novelization; scenario; screen adaptation. 